\title{
Analysis of the Development Trend of Online Education in China
}

\author{
Shen Zheng \\ Department of Educational Technology, Quanzhou Normal University, Quanzhou, China \\ Email address: \\ 18259590303@163.com \\ To cite this article: \\ Shen Zheng. Analysis of the Development Trend of Online Education in China. Education Journal. Vol. 6, No. 5, 2017, pp. 159-163. \\ doi: $10.11648 /$ j.edu.20170605.13
}

Received: August 13, 2017; Accepted: October 5, 2017; Published: October 27, 2017

\begin{abstract}
In recent years, China's online education has developed in a raging fire, and new products have been springing up, gaining more users' recognition and attracting more and more investors and developers. It's a chance more than a challenge for education informatization. As educators, it is very necessary to make a sober analysis of the current situation, trends and reference points of online education. This paper analyzes the development characteristics of online education market in China in recent years, and introduces the classification of current online educational products in detail.
\end{abstract}

Keywords: Online Education Market, Online Education Products, Online Interactive Classroom

\section{Introduction}

Dickens, a famous English novelist, wrote such a sentence in his famous book "A Tale of Two Cities": "It was the best of time, it was the worst of times." The same goes for practitioners in China's Internet industry today. The rapid development of the Internet, on the one hand, presents the explosive growth of information, people's demand for knowledge are becoming more and more diverse; on the other hand, also provides a new platform for the development of the education. In 2012, the development of online education in china just entered the preheating state, but its market share reached 72.3 billion yuan by the end of 2012. In 2013, with the influx of a large number of capital, the number of online education enterprises in China showed geometric growth. At the beginning of 2014, the BAT (Baidu, Alibaba, Tencent), leaders of the Internet giants, began to seize the online education market. At the world Internet Conference in 2014, Alibaba's boss, Ma Yun, expressed his view: "in the Alibaba's investment plan list for the next ten years, education is at the top." [1]

\section{Main Features of Online Education Market in China}

\subsection{Scale of Online Education Market in China}

The trend of Chinese online education market is shown in Figure 1. According to the figure, online education has woken up and the market has begun to flourish. In 2010, the size of national online education market was only 48 billion and 520 million yuan. After 2013, the growth began to accelerate. In 2015, the number reached 148 billion and 260 million yuan. The market is expected to reach 188 billion and 590 million yuan by 2016. [2] In previous years, the development speed of online education market is not very fast, although its market volume is not small, it takes time for user who has long established learning habits and consumption habits to change. For some online courses, the concept of reverse is not only about students, the more important is about parents. 


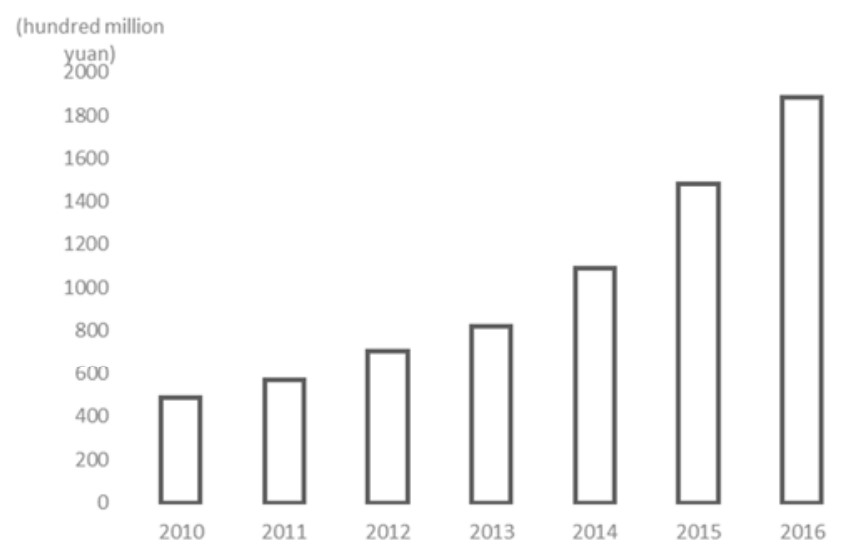

Figure 1. The trend of online education market in China.

\subsection{User Scale of Online Education in China}

The scale of users in China's online educational sector is as shown in Figure 2. We can see from the figure that since 2013, the quantity of online educational user has started to increase fast. Before 2013, the annual increasing rate of users is under 20 percent every year. In 2013, the rate of increase of users is only 8.6 percent. Since 2014, the rate of the increase of users continued to rise. It is predicted that the population of online educational users will exceed 120 million. At that time, the speed of revolution in traditional educational institution will quicken gradually. With the drive of the Internet development, the cover rate of online educational method will improve rapidly. Aside for some forbenefit institution or products, schools or some official educational institution will also accelerate the speed of the construction of online education under the tide of Internet.

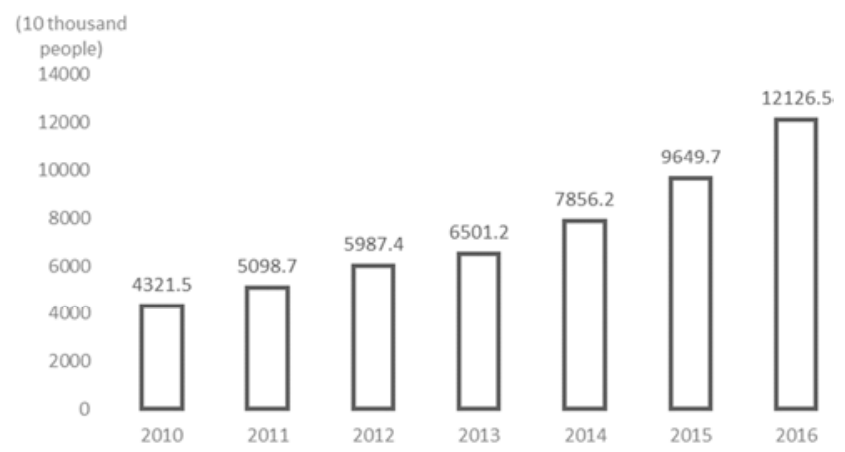

Figure 2. China Online Education Industry User Size.

\subsection{The Investment Structure of Online Education Market in China}

In the investment structure of online education market in China, K-12 education has its own large market requirement, and it also takes the largest proportion about 25.7 percentages among all the current investment projects. The projects of language training, occupational training and further education abroad are primary market investment. The proportions of each project are $14.4 \%, 12.5 \%, 12.4 \%$. [3] Education with record of formal schooling and the interesting courses are also some popular project. Nowadays online education in China is still in an inferior period, and online education still pay more attention to practical training which is immature in the market that all kinds of online education didn't be divided clearly. With the improvement of our knowledge about online education, it will be a great profitable educational project on future interests and the capacity of independence.

\subsection{The Interest Degree of the Interest Course Is the Highest}

As we can see in the specific course type, interest classes attract the highest attention of people which takes up $28.2 \%$, while occupational skills classes take up $17.1 \%$, language study classes take up $15.4 \%$, college education classes take up $10.8 \%$. While other courses' percentages are all less than $10 \%$, all these can be seen in Figure 3. With the rapid popularization of online education and the increase awareness of study by themselves, more and more people would prefer to study what they like themselves and improve themselves on their own initiative. [4] So that we can make it impossible to promote the development of interest class, and that everyone can have chances to study the fields they like by a lower cost. After all, individuation is the theme of this interest age.

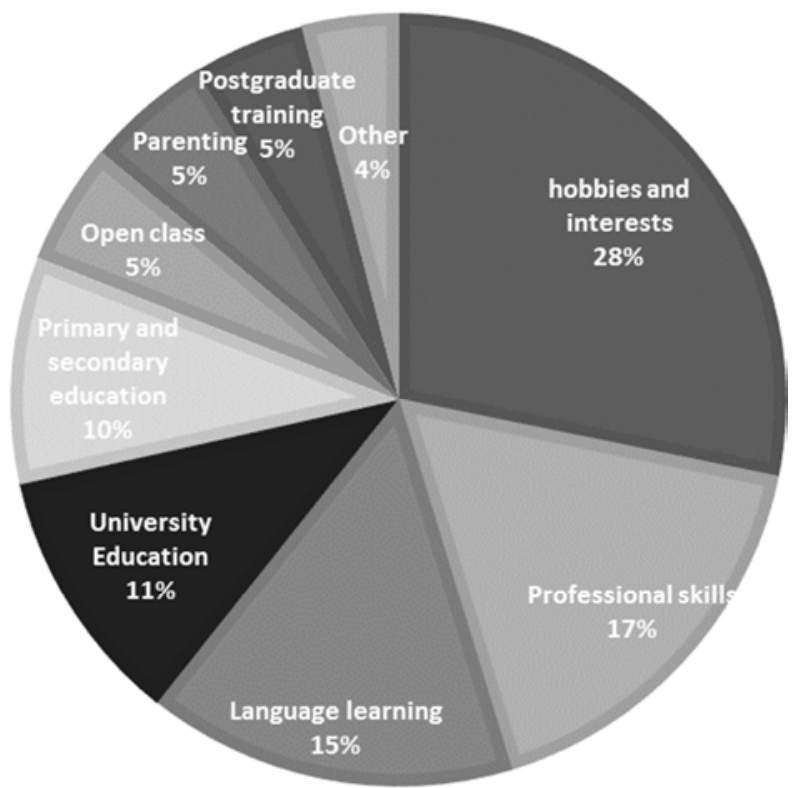

Figure 3. Distribution of User Attention in Online Education Courses.

\subsection{The Model of Online Education Promotion Is Mainly Based on Online}

Survey result shows that users get the cognition of online education are mostly from one-line; mainly from the recommendations of websites and social media, and account for $35.2 \%$ and $31.8 \%$. The users through the introduction of friends and the recommendation of teachers account for $12.1 \%$ and $8.9 \%$. The users through the newspaper and advertisements only account for $5.1 \%$ and $4.4 \%$. By using the method of online to extend the educational courses, not only 
raise the speed of spread, but also lock the users in the Internet users, such as the Internet productions users like micro-blog and we chat, the acceptance is higher by comparison.

\subsection{The Content of Online Course Is the Most Important}

The main consideration factors about the users' choice of online courses are showed as Figure 4. As the chart shows, users place the content first, taking up $45.2 \%$ of them. The resource of famous teachers takes up $35.1 \%$, while the importance they attach to the price is at the third place, only taking up $35.1 \%$. The market of online course is faced with regarding the content as a king and the guiding of famous teachers, which there are not big differences between with traditional methods of education. Online courses go without the popularity of traditional organization of education and the setup of assessment, so their requirement of famous teachers is higher, otherwise it will be difficult to improve the stickiness of users. But in terms of further development, the importance of course content will gradually decrease, if online education can bring us innovation in teaching method and build a perfect system to examine.

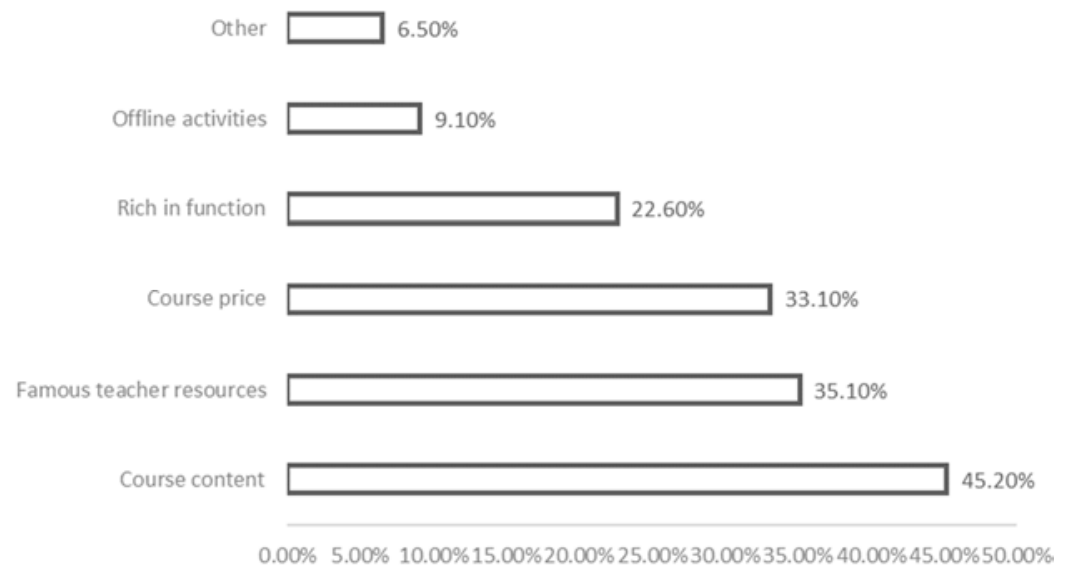

Figure 4. The Main Consideration Factors About the Users' Choice of Online Courses.

\section{Introduction of Current Online Education Products}

Online education product classification can be carried out from multiple perspectives: from the perspective of the development of the main industry, it can be divided into professional education institutions and general business institutions; from the angle of the education stage, it can be divided into $\mathrm{k} 12^{\prime}$ vocational education, higher education, continuing education and other stages of online education products; from the point of view of the product or service provided, it can be divided into resources, tools, platforms and other online education products; from the point of view of issuing a certificate, it can be divided into academic education and non-academic education. [5].

While there are many organizations investing in online education, the focus of purely educational versus commercial organizations is quite different. This paper will introduce these two types of educational institutions and contrast similarities and differences between the two.

\subsection{The Online Educational Products of Professional Education Institutions}

The online educational products of Professional education institutions are still dominated in content of courses, but it pays more attention to the management of resources and the user experience during the process of providing the content of courses, and added more personalized service. What's more, professional education institutions have begun to develop various education tools, such as online education platform, education navigation, specialized search engine and so on.

\subsubsection{Unidirectional Online Education Resources}

Typical cases of unidirectional online education resources mainly include electronic teaching plan, course video, exercises, digital teaching materials and Micro Learning Resource which are popular in recent years. This kind of products have been developed for many years, the form of them are traditional and lack of interactivity. [6] With the development of online education, the attractions of the users are reducing gradually. But in recent years, there have been some beneficial changes, such as micro lessons. Its teaching time is short, the subject is prominent, it is easy to store and spread, and it is convenient for teachers to help teaching and students self-study and so on. All these features have made micro lessons draw attention from all walks of life.

In the past two years, a variety of micro competitions come forth. Such as the national primary and secondary school teachers based national micro teaching competitions. There are a variety of micro course resources website, such as micro course network, China micro class network, etc. Set up a micro Curriculum Resources Sharing Alliance to study the micro curriculum standards and micro curriculum resource sharing foundation operation [7]. Also appeared a lot of micro course design and production research activities. 
The generation of Micro Leaning Recourse is a great progress of traditional educational resources products, which reflects the granulation of resource development, management and use, and more suitable for the current user needs.

\subsubsection{Interactive Online Education Resources}

Such products are improvements in traditional online educational resources in another direction, with greater emphasis on their interactivity. The main products are educational games, educational cartoon, virtual simulation software and personal question and so on. Educational games and cartoon mainly concentrate in the low age group such as the $\mathrm{Wu}$ Kong Shi Zi. Virtual simulation software mainly faces to higher education and vocational education. The Ministry of education planned to build about 100 national level virtual simulation experimental teaching centers in 2013, which ignited the enthusiasm for building virtual simulation laboratories in Colleges and universities. There are still many enterprises that focus on the virtual simulation software in education field besides colleges and universities. These enterprises will cooperate with the schools in the actual development and develop virtual simulation software which conform to with the requirement of individuation. This kind of products mainly include Ti Zi Wang, Kuai Le Xue, Yi Qi Zuo Ye and Yuan Ti Ku and so on. The characteristics of this kind of are mainly detailed question bank management, convenient function in volume, personalized analysis report and resource recommendation and so on.

\subsubsection{Online Interactive Classroom}

MOOCs, short for Massive Open Online Course, is a typical representative of such online teaching products. In 2012, there occurred an educational storm of MOOCs over the world, led by the world's top universities like Harvard, Stanford, MIT and so on. The tendency of MOOCs was introduced into China in 2013, and due to its characteristics of high quality and opening style of teaching resources, strong interactivity, and independently study progress arrangements, MOOCs gained great recognition among Chinese learners in no time flat. [8] Afterwards, China's MOOCs curriculum and platforms began its construction by colleges and enterprises in China. So is the establishment of organizations like the Course-Sharing Alliance in Eastern and Western Universities. In this way, it will jointly promote the construction of MOOCs and the transformation of traditional classroom teaching mode and the co-sharing of high quality of educational resources. In addition, various MOOCs research centers, seminars, symposia, competitions are invariably springing up. [9]. But apart from MOOCs, the one-to-one or one-to-more live teaching methods like 51 talk and Alibaba's newly invested VIPABC course also belong to this category.

\subsubsection{The Tools of Online Education}

Online education tools develop rapidly, how to help teachers to adaptation and make online lessons for them, organizing online teaching to provide convenient tools to become a joint effort of many professional education institutions and general business institutions. Professional education institutions online education tools to explore two categories: first, online course production tools; the two is the teaching tools.

\subsubsection{Education Navigation, Search Engine}

How to quickly and accurately locate the information is the problem encountered by many Internet users, but also search engines, navigation, construction units continue efforts to power. How to help learners to accurately locate the necessary educational resources, services also attracted the attention of search engine providers and specialized educational institutions. Special education institutions in this regard are the main efforts: (i) desktop, navigation. Such as www.links123.com summarizes and guides current online education websites of nearly 600 , while providing keyword retrieval services. (ii) educational resources search engine, that is, search to the content of educational resources, these products are more attached to the internal education network resources, the scope of the search is limited to this site, such as Edugo. At present, the National Education Resource Public Service Platform is also building a professional education search engine that can search the whole internet education resources.

\subsection{General Business Organization}

Online education has executed in full swing, in addition to the original institutions, and keep up with the form of continuous efforts, at the same time, also attracting a lot unconcerned commercial institutions pay attention to the field of the education, such as BAT(Baidu、Alibaba and Tencent). There is difference between orientation of general commercial institutions and professional bodies, and developing education content is less than before, providing matching tools and platform, searching and all kinds of technologies and offering varies of solutions services.

\subsubsection{Survey on the Development of Online Education}

Through online education survey and annual festival ceremony, it is the choice of many institutions to understand the development of online education, to analyze their own advantages, and to find the opportunities and ways to enter online education. In 2013, www.sina.com.cn, www.163.com, and www.youdao.com as well as other companies and institutes have released survey reports of online education, they all investigated comprehensively the status of the development of online education. Tencent, Baidu, www.sina.com.cn, www.163.com, www.sohu.com, www.xinhua.com have held annual meetings of education and festival activities one after another, for awarding and ranking to the companies of online education, and understanding the developmental status of online education, looking for opportunities to improve themselves.

\subsubsection{The Tools of Online Education}

General business institutions in education, mainly dedicated to the teaching tool. Tencent QQ and YY Voice is 
through the teaching tool to enter the field of online education. YY Voice changed the original design of group chat tool for teaching which was designed for game player. QQ also increased the mode of teaching in the group chat mode. YY and QQ are independent teaching tools. In addition, there are a lot of teaching tools with a complete set of online education platform. Get into the field of education through the teaching tools, it already has a considerable number of users. Just a simple transformation and then transplanted to the field of education. However, the simple educational tools are not competitive in the field of online education, so the two companies are constantly trying to do somethings to improve.

\subsubsection{The Platforms of Online Education}

Teaching platform is a field which general commercial organization can entered online education easily in addition to the professional educational institutions. The efforts made by general commercial organization in this respect are of two main types: partly to buy a fully-fledged online educational platform, partly to build a self-existent platform. For example, Baidu bought into www.chuanke.com which features live interaction online in December 2013, and managed to enter the online education; meanwhile, Baidu offered Du School in Baidu Education to create a classroom online which has an enormous amount of free resources, and strengthen self-owned level gradually in January 2014. On the contrary, Alibaba built Taobao Tong Xue, an online educational platform, to try best to construct the learning ecology in February 2014; moreover, Alibaba injected TutorGroup to build an English school website named VIPABC for English learner in the Chinese region which further enhanced its strength in the field of online education.

\subsubsection{Resources of Online Education}

General commercial institutions' major business is not education, so their educational resources are provided by some professional organizations or learners. They rarely develop their own resources, not only a few of them have independent educational resources but also concern in their own areas of superiority. For example, Tencent launched Tencent University in February 2014, to conform the resources of the Tencent university that originally serves internal training. At the same time, they work with other educational companies to carry out electronic business by combing live network, live video and offline training.

\subsubsection{Technology or Program Services}

Online education is a cross industry field, and it requires knowledge in many areas, such as education, computer science, marketing and so on. At present, online education is in the exploratory stage, has not yet formed institutions with multifaceted abilities, so there are a lot of institutions providing technical or program services, such as Inspur provides platform construction for traditional educational institutions.

\section{Conclusion}

Online education is developing towards a diversified profit model and educational products' personalization. The traditional educational institutions and online education institutions have begun to develop mobile education products, led by BAT, internet companies have started in the mobile terminal cross layout, mobile education is the outbreak of the future of online education market. In addition, due to the high demand for personalized mobile terminal products, the application of big data analysis technology will also be necessary. Based on user requirements and the rule of the habit of digging, innovation content and teaching methods, the online education companies can set up perfect credible learning evaluation system. [10] Online education has developed rapidly, which attracts investment from all walks of life. It's a chance more than a challenge for education informatization. The face of change, we can't rest on its laurels, should take the initiative to grasp the development trends of online education.

\section{References}

[1] Yang, Y. Research on the Development of Online Education Platform in China. China Management Informationization, 2016, Vol.19, pp.245.

[2] Wang, C. and Liu, N. 'Internet + Education' Great Changes in Education in the Mobile Internet Era. China Economic Publishing House, Bengjing, 2015.

[3] Cai, K. Facing K12's "Pain Spot", Online Education can "Nirvana". Twenty-first Century Economic Report, 2015, Vol.115, pp.1.

[4] Ni, J. L. 36kr Online Education Column [EB/OL]. $\mathrm{http}: / / \mathrm{www} .36 \mathrm{kr} . \mathrm{com} / \mathrm{tag} /$ online education.

[5] Yang, J. F. 'Internet + Education' New Learning Revolution. Intellectual Property Press, Bengjing, 2016.

[6] Zhang, H. and Yang, L. H. Learner Experience Design in A Micro Content Environment. Proceedings of the fifth national Doctoral Forum on Educational Technology, 2009, pp.35-38.

[7] Wen, C. New Industrial Revolution and Network Education. The New Economy, 2014, Vol.217, pp.35-38.

[8] Chen, M. P. MOOC Leads the Change of Learning Mode. Industrial \& Science Tribune, 2014, Vol.13, pp.178.

[9] Long, J. H. and Wu, S. Discussion on How MOOC Promotes Local Universities to Train Applied Talents. Modern Computer, 2015, Vol.15, pp.54-57.

[10] Pan, X. F. Research on Online Education Industry Development and Product Design. Science Technology and Industry, 2013, Vol.13, pp.13-16. 